\title{
Calculation of Achievable Altitudes for Hydrogen Fuelled Fuel Cell Powered Unmanned Air Vehicles with Rocket Boosting
}

\author{
Nevzet Kaya
}

\begin{abstract}
Deficient power to weight ratios of fuel cell power systems does not allow achievable altitudes over 8-9 km for unmanned air vehicles (UAVs). This is mainly due to high power requirement of air vehicles all along the take-off and climb phase leading their powertrain, including the fuel cell, electric motor and inverter systems, to operate at off-design conditions soon after the take-off. A rocket boosting during climb can both allow to design the UAV's powertrain for their nominal operating conditions at the latest stages of climb and/or cruise phase and significant weight and fuel saving, hence higher achievable altitudes. In this paper, achievable altitudes with rocket boosting during climb is investigated for all air vehicles but especially for FC powered hydrogen fueled UAVs. The UAVs were characterized/investigated by their thrust to weight ratio (TWR), drag to weight ratio (DWR) and stall speeds at sea level, while the rockets were characterized/investigated by their gas exit speeds only. Results indicate that there is almost no restriction, other than the available propellant onboard, restricting the achievable altitudes. The most significant parameters determining the achievable altitudes, with a certain amount or fraction of propellant are gas exit speeds of the rocket and stall speed of the air vehicle. DWR of the UAV has a negative but little effect on the achievable altitudes, as long as it is not worse (higher) than some reasonable values. TWR of the UAV has two opposite effects on the achievable altitudes, hence requires optimization.
\end{abstract}

Index Terms - Fuel Cell, Solid Fuel Rocket, Unmanned Air Vehicle.

\section{INTRODUCTION}

Unmanned Air Vehicles (UAVs) have been challenging manned aircrafts both in military and civilian applications since the last two decades, owing to their many advantages in tactical, technical and economic aspects. Actually a UAV can perform any mission currently performed by manned aircrafts with better performances, higher efficiencies, lower costs and risks. They have already dispossessed, either largely or partially, some military missions such as surveillance \& reconnaissance and some civilian missions such as monitoring and filming from manned aircrafts. There are some missions which are not well suited for human, such as those requiring long, heavy or dull activities. Besides, there are some missions which can never be performed by manned aircrafts but UAVs, such as operating in a dirty, dangerous or narrow environment. Therefore, it is not an unreasonable dream to think UAVs will dominate over manned flights in many applications. Actually, current technology is almost ready for and it seems to be mainly regulatory issues retarding this dream to come true [1-5].

Anadolu University, Faculty of Aeronautics and Astronautics, 26470, Eskişehir, Turkey
Fuel cells are the companions of the UAVs in presenting better features with respect to their counterparts, such as higher efficiencies, higher design flexibility, numerous fuel choice and lower environmental effects, just in a different field, that is energy conversion, by its turn. Nevertheless, fuel cells are not at the state of challenging their counterparts seriously in power densities yet [6-8].

Hydrogen is a clean and abundant energy carrier, well suited both for fuel cells and internal combustion engines in terms of sustainability concerns. Nevertheless, low storage capacity of hydrogen is a significant issue impeding its wide use in mobile applications, especially in aviation [9-10].

Maximum achievable altitude is a key performance parameter for a UAV determining its suitability for a mission. First of all, a UAV has to be capable of achieving the mission altitude, which is not always directly related to power and propulsion system efficiencies and amount of fuel onboard, but its propulsion and aerodynamic characteristics such as thrust to weight ratio and drag to weight ratio as well. Both currently deficient fuel cell power and hydrogen storage densities do not allow hydrogen fueled fuel cell powered aircrafts even to achieve altitudes $8-10 \mathrm{~km}$ [11], while the best missions for UAVs, such as communication relays, geosynchronous and Low Earth Orbit (GEOs and LEOs respectively) applications require cruising over $15 \mathrm{~km}$ altitudes. Main reason lying behind this deficiency is high fuel stack (FCS) weight, which has to be designed for meeting the nominal power requirement at take-off. However, the power requirement of an aircraft for propulsion is much less at high altitudes than its requirement during take-off. Propulsion power requirement of an air vehicle at $16 \mathrm{~km}$ altitude is about $10 \%$ of its TO value for example. This means, up to $90 \%$ of savings from FCS weight are possible, if the FCS is designed to operate at its maximum power at the mission altitude of the air vehicle. At least, some weight savings about $50 \%$ are quiet reasonable, if it is considered that FC efficiencies are higher at lower loads. Then, the problem is how to bring the air vehicle to its mission altitude, if this cannot or will not be done by its normal/permanent power generating system, that is the FCS. The answer is some temporary propulsion system. Rockets, which are exempt from propulsion degradation due to ambient air pressure and density, can perform this mission very well. Moreover, they will allow saving from the fuel used for climb, hence longer cruise times. I have chosen the solid fuel rockets, as they require minimum number of elements, discarding extra fuel and oxidant tanks, pumps or compressors, combustion chambers and/or piping. 


\section{BACKGROUND}

\section{A.Fuel Cell Principles and Technology}

Fuel cells are electrochemical devices, which deliver electrical power as their main output and some heat as their waste or secondary output. Operating principle of the fuel cells depend on ionization of either one or two reactants (the fuel and the oxidizer), either directly or by the help of a catalyst, on two electrodes separated by an electrolyte which permits only one of the reactants to pass thorough. If the two electrodes are connected by an external electrical path, the mobile reactant moves through the membrane, meets with the other reactant and the electrons on the opposite electrode where the reaction takes place. In this way, one of the electrodes serves as a charge source and the other as a charge sink, making an electric current to flow thorough a load as shown in Fig.1. Due to some technical concerns, such as requirement of a porous structure (for ion passage) and a high contact surface area (for higher activities) the electrode, electrolyte and catalyst assembly is made in form of a mixed sludge in general. Therefore, strength of the assembly has to be provided externally. This is done by bipolar plates, which perform charge collection and fuel and oxidizer circulation functions as well.

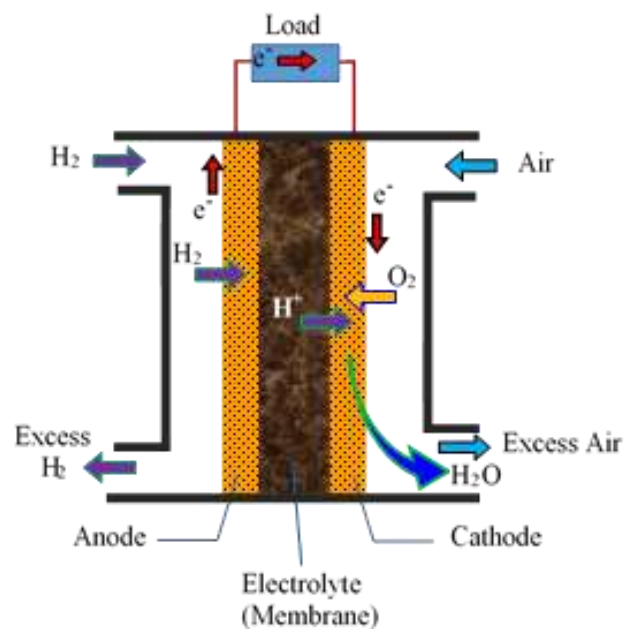

Fig.1. Elements and operating principle of a hydrogen fueled air-fed fuel cell

Electrical potential/voltage generated by the fuel cell reaction is around $1 \mathrm{~V}$ or less in general, which is very low for power applications. D.C. current required for $1 \mathrm{~kW}$ power output is $1000 \mathrm{~A}$, for example. Beside presenting high resistive losses, it requires very large active surface areas of electrodes and catalyst to produce such a high currents (active surface area required for $1 \mathrm{~kW}$ output in the above example is greater than an A4 paper size for example). However, as reactant concentrations over the electrode and catalyst surface decreases from their feeding points/sections on, as they are used up by the reaction, effective surface ratio on large fuel cells are less with respect to small fuel cells. As the bipolar plates thickness have to be the same or even higher for larger surfaces, to provide the same strength, FC power densities are lower for large surface FCs with respect to smaller ones. For example, the output power density of a single cell with a surface area of $16 \mathrm{~cm}^{2}$ can reach $0.4 \mathrm{~W} / \mathrm{cm}^{2}$ at $750^{\circ} \mathrm{C}$, while the power density of a $100 \mathrm{~cm}^{2}$ cell is usually $0.2 \mathrm{~W} / \mathrm{cm}^{2}$ at the same temperature [12].
Increasing operating pressures, for increasing the reactant activities, requires higher mechanical strength hence higher weights of the flow channels, which have to be of electricaly cunducting material. Besides, higher operating pressures result in fuel cross-over, such that both the permitted and non-permitted reactants pass into the membrane and react there, without generating/pushing an electrical current thorough an external circuit. All these end up with about $0.6 \mathrm{~kW} / \mathrm{kg}$ or less electrical power densities of acual fuel cells [13-14], which is quiet deficient for aviation applications, where weight is a major concern.

Fuel cells are electrically connected in series, forming fuel cell stacks (FCS), where FCS voltage is equal to the voltage of a single FC multiplied by the number of FC connected in series. In this way, the same electrical power is provided with lower currents. Even this method ameliorates the resistive loss and weight problems to a certain extent, it is still away from being satisfactory due to large thrust requirement/availability variation of the air vehicles with altitude. This makes the UAV's powertrain to operate at off-design points, resulting in significant efficeincy and effectivity decreasses of the system elements. May be the most susceptible element to this disadvantage is the fuel cell itself. For example, fan loading of a UAV at $14 \mathrm{~km}$ altitude is about $13 \%$ of its value at sea level, as can be seen from Fig.2. Therefore, an UAV has to carry almost for vain about $87 \%$ of the FC system weight designed for TO conditions, restricting the ecess thrust, hence its achievable altitudes. However, a moderate decrease in the UAV's weight would allow a significant increase in achievable altitudes.

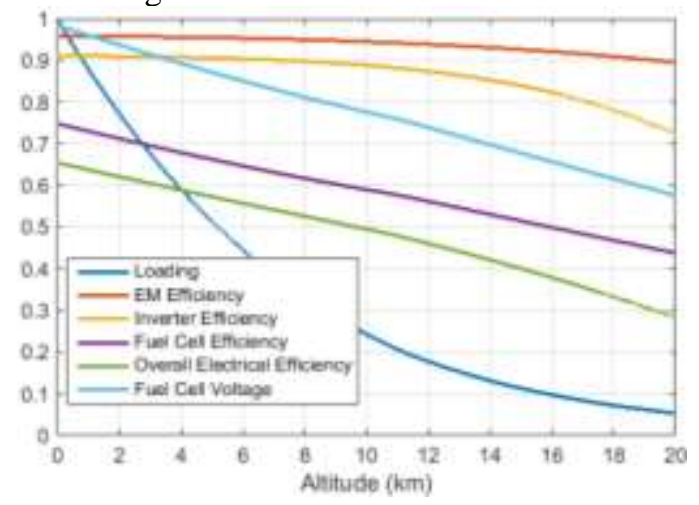

Fig.2. An example of loadings and performances of a FC powered propulsion system elements designed for UAV applications [11].

\section{B.Rocket Principles and Technology}

Thrust generation principle of a rocket depends mainly on Newton's second and third laws of motion. When a part of the rocket (its burned fuel), such as an Fig.3, is accelerated by forces due to pressure gradient through the chamber of the rocket, it applies a force equal in magnitude and in opposite direction to the rocket. Besides, pressure difference between the inside and outside of the nozzle's exit section applies a pressure force relatively small with respect to the accelerated gasses. The resultant force can be described as,

$$
F=\dot{m}_{e} \cdot\left(v_{e}-v_{0}\right)+A_{e} \cdot\left(P_{e, s}-P_{0}\right)
$$

if the drag force resulting from the ambient air friction over the rocket surface is ignored. $P_{e, s}$ becomes equal to $P_{0}$ if the gasses are fully expanded to the ambient pressure at the nozzle 
exit, which is the case with a great approximation in general. Therefore, equation (1) can actually be considered as,

$$
F=\dot{m}_{e} \cdot\left(v_{e}-v_{0}\right)
$$

with a great approximation.

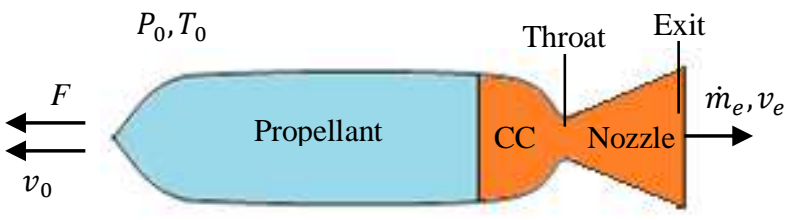

Fig.3. Thrust generation principle of a rocket

Thrust is directly proportional to mass flow rate and average exit speed of the gasses from the rocket, as can be seen from equation (2). As higher mass flow rates mean faster depletion of the fuel, higher thrust efficiencies (specific impulses) require higher gas exit speeds, rather than higher mass flow rates. However, gas exit speed in a convergent or constant sectional area duct is limited by the speed of sound at the static temperature of the gasses at the exit section, which is not enough for obtaining necessary thrusts in general. Therefore, convergent-divergent ducts are used to accelerate the gasses to supersonic speeds. Gas exit speeds are a function of the gas thermodynamic characteristics (such as gas constant $R_{g}$ and specific heat ratio $\left.k_{g}\right)$, total pressure $\left(P_{e}\right)$, total temperature $\left(T_{e}\right)$ and ambient pressure $\left(P_{0}\right)$, in such a way that,

$$
v_{e}=\sqrt{\left[1-\left(\frac{P_{e, t}}{P_{e, s}}\right)^{\frac{1-k_{g}}{k g}}\right] \cdot \frac{2 \cdot k_{g}}{k_{g}-1} \cdot R_{g} \cdot T_{e, t}}
$$

Indeed, $P_{e, t}$ and $T_{e, t}$ are the pressure and the temperature in the $\mathrm{CC}$ respectively, if the flow is assumed to be adiabatic and pressure loss through the nozzle is ignored. Higher gas exit speeds, hence higher specific thrusts, require higher pressures and temperatures in the CC, as can be seen from equation (3). Theoretically achievable temperatures in the $\mathrm{CC}$ are limited by the adiabatic flame temperature of the fuel, while practically achievable temperatures are determined by the actual material endurance to such a high temperature. Practical CC pressures are limited by material strength and construction technology too. The oxidizer can be brought in separate tanks, taken from the ambient air or contained in the fuel thorough chemical bonds. Bringing the oxidizer onboard requires huge storage tanks, hence is not practical in many cases, except in some spacecraft applications. Taking the oxidizer from the ambient air requires compressors, hence an increase in weight, to increase the air pressure up to the pressure in the CC. In my opinion, bringing the oxidizer thorough chemical composition of the fuel, as in the case of solid propellants, is the optimum choice for direct rocket applications, as well as using them as boosters in the climbing phase of an UAV. Moreover, solid fuel (propellant) rockets are simpler and cheaper. Even the burning reaction, hence the thrust generation, is almost out of control once it is started, it can be predetermined by the burning surface geometry of the propellant such as given in Fig.4.

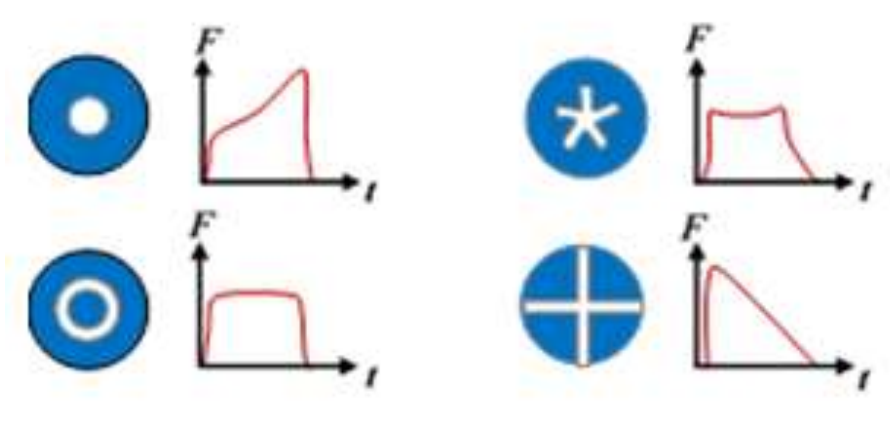

Fig.4. Sections and thrust generation characteristics of solid fuel rockets as a result of burning surface geometry (adapted from [15]

\section{METHODOLOGY}

\section{A. General Assumptions}

The UAVs were assumed to climb with the rocket propulsion only, in the US Standard Atmosphere 1976 and steady air, on a straight path or with a sufficiently large turn radius such that any extra lift requirement for turn is ignored. The rockets were assumed to contain $90 \%$ solid propellant as their mass and all of the propellant was assumed to be consumed in take-off run and climb phase. Burning surface area of the propellant was assumed to be constant, presenting a constant burn rate and delivering a constant thrust all along the climb. Total weight and extra drag of the rockets were not taken into account privately, but in the varied drag to weight ratios of the UAVs. The UAVs were assumed to climb with the minimum airspeed (indeed the minimum dynamic pressure) necessary and enough for a safe control of the air vehicle at any altitude (which results a constant drag force) all along the climb. The UAVs were assumed to climb with the maximum available climb angle, which is a function of the excess thrust and acceleration requirement of the UAV. Mass flow rates of the rockets were calculated according to thrust to weight ratios determined for take-off, assuming the exit gasses to fully expand to ambient pressures. The UAV's TOWs were calculated taking into account both the decrease in the fuel cell system weight, including that of FCS, electric motors, inverters, as well as addition of the rocket weights.

\section{B. Variable and Constant Input Parameters}

Ranges of input parameters and some constant are shown in Table 1. Maximum achievable altitudes were investigated with respect to some pairs of variable input parameters, while taking all the others as constant. It has to be noted that, achievable altitudes of the UAV are not determined by the exact values of its TOW, thrust, drag and propellant mass, but rather by the ratios such as TWR, DWR and propellant mass to TOW ratio, as well as the stall speed of the UAV and the specific impulse of the rockets. 
TABLE I

VARYING INPUT PARAMETERS USED For CALCULATION

\begin{tabular}{|c|c|c|}
\hline Variable Input Parameter & Min. & Max. \\
\hline$D W R$ of UAV & 0.02 & 0.05 \\
\hline$T W R$ at Take-Off & 0.1 & 0.9 \\
\hline Stall Speeds of UAV at Take-Off $\left(v_{00}\right)$ & $10 \mathrm{~m} / \mathrm{s}$ & $50 \mathrm{~m} / \mathrm{s}$ \\
\hline Gas Exit Speeds of Rockets $\left(v_{e}\right)$ & $2 \mathrm{~km} / \mathrm{s}$ & $6 \mathrm{~km} / \mathrm{s}$ \\
\hline \multicolumn{3}{|l|}{ Constant Parameter } \\
\hline \multicolumn{2}{|c|}{ Base UAV's FC Power Sys. Design Power at TO } & $100 \%$ \\
\hline \multicolumn{2}{|c|}{ Rocket Boosted UAV's FC Sys. Design Power at TO } & $13 \%$ \\
\hline \multicolumn{2}{|c|}{ FC Sys. Weight Fraction in the Base UAV's TOW } & $25 \%$ \\
\hline \multicolumn{2}{|c|}{ Decrease in FC Sys. Weight (through rocket boosting) } & $80 \%$ \\
\hline \multicolumn{2}{|l|}{ Rocket Weight Fraction in TOW } & $33 \%$ \\
\hline \multicolumn{2}{|c|}{ Propellant Mass Fraction in the Total Rocket Mass } & $90 \%$ \\
\hline \multicolumn{2}{|c|}{ Final Weight Increase in the Rocket Boosted UAV } & $20 \%$ \\
\hline
\end{tabular}

\section{Calculations}

The first step was to calculate and register the ambient air pressures and temperatures in between 0 to $40 \mathrm{~km}$ altitudes, according to the relevant formulas and constants given in US Standard Atmosphere 1976, thorough a MATLAB code. Ambient air densities in the same range of altitudes were calculated from the ideal gas law. The next step was to calculate the mass flow rate of the rocket's propellant from,

$\dot{m}_{\text {prop }}=\frac{F}{v_{e}}=\frac{T W R \cdot T O W}{v_{e}}$

Stall speed of the UAV at an altitude $h$ was calculated from,

$v_{0}(h)=v_{00} \cdot \sqrt{\frac{\rho_{00}}{\rho_{0}(h)}}$

Referring to Fig. 5, the force balance on an aircraft during climb is given by,

$F=D+W_{U A V} \cdot \sin (\beta)+\frac{a}{g} \cdot W_{U A V}$

Assuming linear accelerations between two adjacent segments of altitudes for calculation,

$a=\frac{v_{0}^{2}(h+d h)-v_{0}^{2}(h)}{2 \cdot d h} \cdot \sin (\beta)$

Therefore, the maximum climb angle was calculated from,

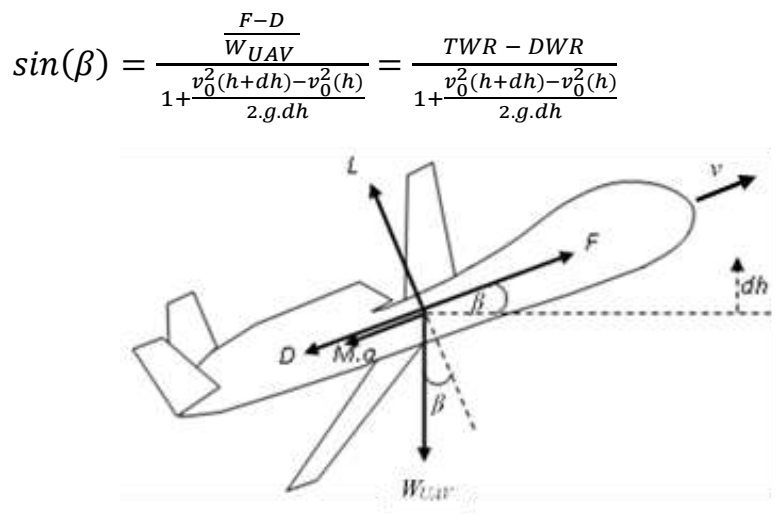

Fig. 5. Force balance on an air vehicle in climb
Calculations were ended when the propellant mass onboard of the UAV decreased below the mass flow rate of the rocket, and the last processed altitude was recorded as the maximum achievable altitude.

\section{RESULTS}

The selected pairs of variable input parameters for which the maximum achievable altitudes were investigated are $T W R-v_{e}$, $T W R-v_{0}, T W R-D W R$ and $v_{0}-v_{e}$. The results are given in Fig. 6 to Fig. 9 respectively.

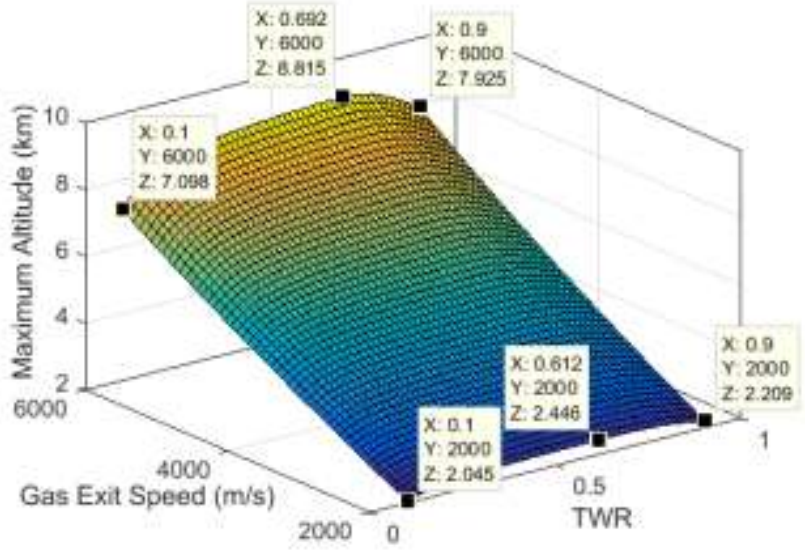

Fig. 6. Achievable altitudes with varying gas exit speeds and TWR at sea level $\left(D W \mathrm{R}=0.025, v_{0}=30 \mathrm{~m} / \mathrm{s}\right)$

Thrust generation of solid propellant rockets are not affected by decreasing ambient air densities at high altitudes. This enables a predetermined excess thrust, hence climb ability, for an air vehicle at any altitude. A UAV can climb to any altitude as long as having enough fuel/propellant onboard.

Figures 6 to 9 indicate that the most significant parameters determining achievable altitudes with rocket boosting are the gas exit speed of the rocket and the stall speed of the UAV. Higher gas exit speeds enable higher specific impulses, providing thrust for longer durations with the same amount of propellant, while higher stall or flight speeds decrease the time for fuel/propellant use.

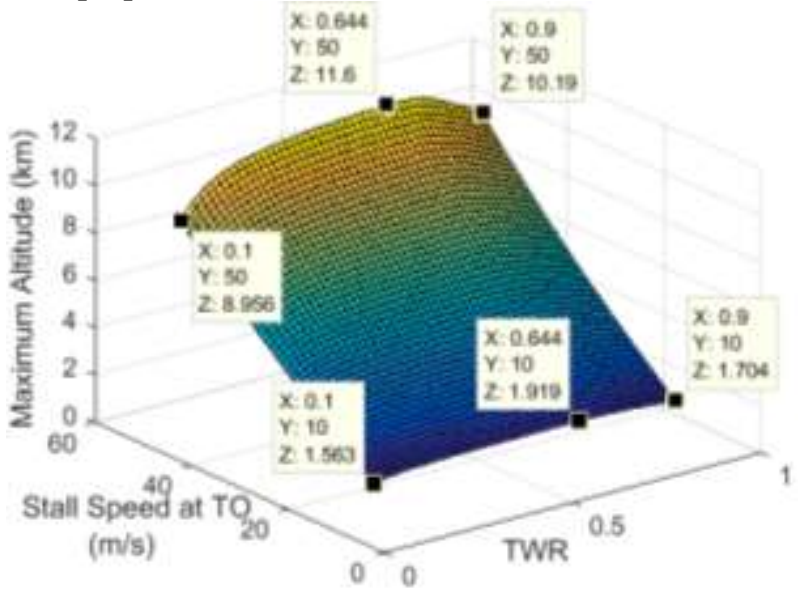

Fig. 7. Achievable altitudes with varying stall speeds and $T W R$ at sea level $\left(D W R=0.025, v_{e}=4000 \mathrm{~m} / \mathrm{s}\right)$ 


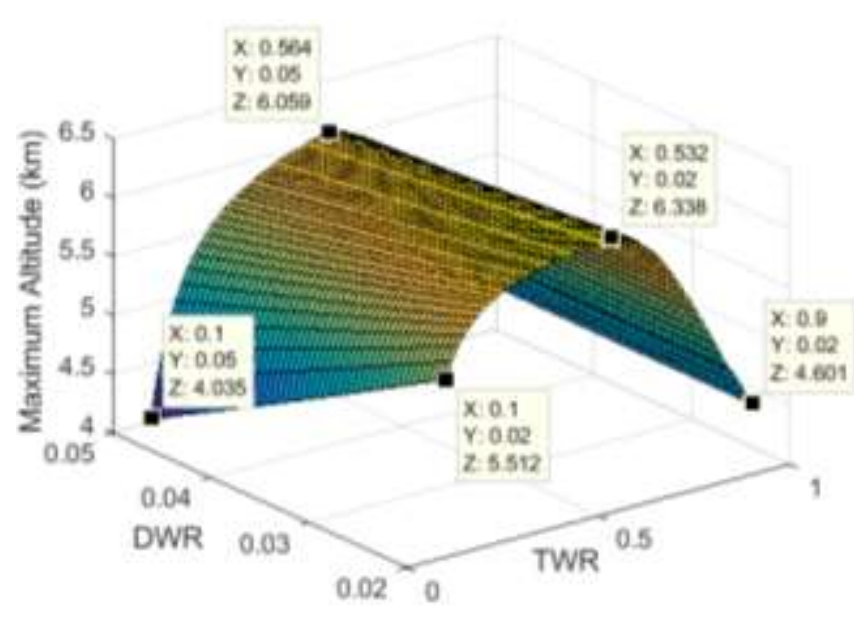

Fig. 8. Achievable altitudes with varying DWR and TWR at sea level $\left(\mathrm{v}_{00}=30 \mathrm{~m} / \mathrm{s}, \mathrm{v}_{\mathrm{e}}=4000 \mathrm{~m} / \mathrm{s}\right)$

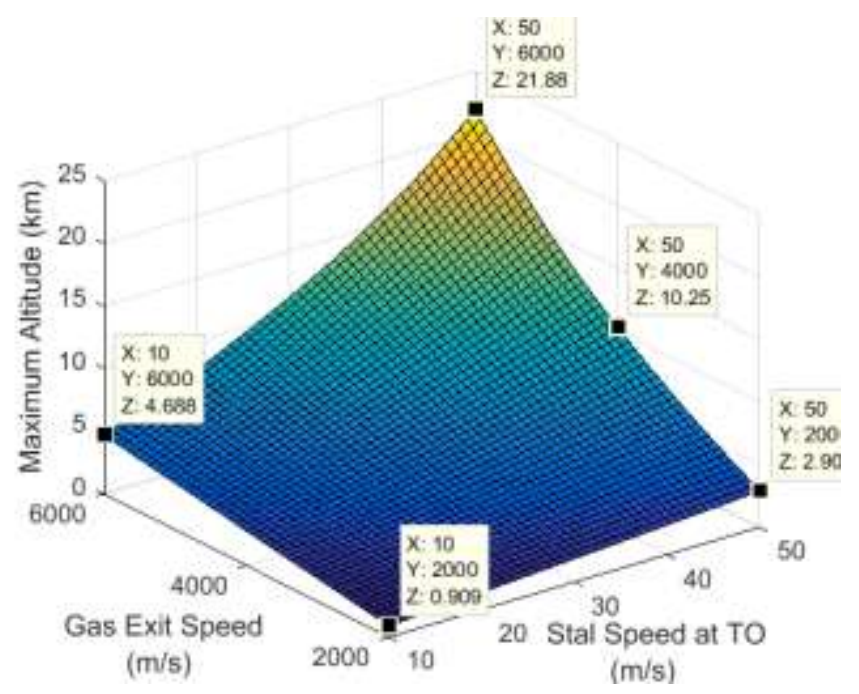

Fig. 9. Achievable altitudes with varying gas exit speeds and stall speeds at sea level $(\mathrm{TWR}=0.4, \mathrm{DWR}=0.025)$

Maximum achievable altitudes are inversely proportional to DWR of the UAV, as would be expected and can be seen from Fig.8. Nevertheless, its effect is minor with respect to stall speed of the UAV and gas exit speed of the rocket.

Higher TWR has two opposite effect on achievable altitudes, the positive one being availability of higher climb angles, hence shorter climb times, while the negative one being necessity of faster fuel use. Therefore, TWRs have some optimum region for the maximum achievable altitudes, as can be noticed from Fig.6 and Fig.7, but can be seen the best in Fig.8.

Fig.9 demonstrates that rockets can bring the UAVs up to very high altitudes, where they can rely on their FC power there on. As the power requirement for thrust is much lower at high altitudes than low altitudes, the FC power system, including its accessories, can be designed for much small sizes and less weight. Besides, all the fuel dedicated for climb can be saved. This is important especially for hydrogen fueled systems, where the actual fuel mass fractions in the storage tanks are very low (below $10 \%$ even for the best case).

\section{CONCLUSION}

Main parameter determining the maximum achievable altitude of an air vehicle is its available excess thrust, which is determined by one part by the thrust generating efficiency of its propulsion system at high altitudes and by its weight by the other part. Fuel cells, being low power density devices, deteriorate much the excess thrust capability of an air vehicle at high altitudes, if designed for the power requirement at take-off. Rocket boosting enables FC powered UAVs, as well as any air vehicle, both to achieve very high altitudes and a significant fuel saving, increasing the cruise times through its latter function as well.

The most significant parameters determining achievable altitudes of a rocket boosted UAV/air vehicle directly are gas exit speeds of the rocket and stall speed of the air vehicle. Higher achievable altitudes require higher gas exit and UAV stall speeds. DWR of the UAV has a negative but little effect on the achievable altitudes, as long as it is not worse (higher) than some reasonable values. TWR of the UAV has two opposite effects on the achievable altitudes, hence may require some optimization.

\section{Nomenclature}

Abbreviations

DWR : Drag to Weight Ratio

GEO : Geosynchronous

FC : Fuel Cell

FCS : Fuel Cell Stack

LEO : Low Earth Orbit

HALE : High Altitude Long Endurance

TO : Take-Off

TOW : Take-Off Weight

TWR : Thrust to Weight Ratio

UAV : Unmanned Air Vehicle

Symbols

$\begin{array}{ll}\mathrm{a} & : \text { Acceleration } \\ \mathrm{D} & : \text { Drag } \\ \mathrm{F} & : \text { Thrust, Force } \\ \mathrm{g} & : \text { Earth's gravitational acceleration } \\ \mathrm{h} & : \text { Altitude } \\ \dot{m} & : \text { Mass flow rate } \\ \mathrm{v} & : \text { Speed } \\ \mathrm{W} & : \text { Weight } \\ X_{L} & : \text { Loading (Actual Load/Maximum Load) }\end{array}$

Subscripts
$00 \quad$ : At sea level standard conditions
$0 \quad$ : Ambient conditions or with respect to ambient
e : : Exit
h $\quad$ : Altitude
s : : Static
t : Total

Greek Letters
$\beta$
: Climb angle

\section{REFERENCES}

[1] Air \& Space Europe, Current and future UAV military users and applications, Air \& Space Europe, Volume 1, Issues 5-6, SeptemberDecember 1999, Pages 51-58.

[2] USA DoD, Unmanned Aircraft Systems (UAS) Roadmap 2005-2030, http://fas.org:8080/irp/program/collect/uav_roadmap2005.pdf

[3] AIA, Unmanned Aircraft Systems: Perceptions \& Potentials, http://www.aia-aerospace.org/assets/AIA_UAS_Report_small.pdf

[4] Cox, T.H., Nagy, C.J., Skoog, M.A., and Somers, I.A., "Civil UAV Capability Assessment, Draft Version", prepared for UAV Vehicle Sector 
Manager, Vehicle Systems Program, NASA Aeronautics Mission Directorate,

https://www.nasa.gov/centers/dryden/pdf/111761main_UAV_Capabiliti es_Assessment.pdf

[5] Kapseong Ro, Jun-Seok Oh, and Liang Dong, Lessons Learned: Application of Small UAV for Urban Highway Traffic Monitoring, 45th AIAA Aerospace Sciences Meeting and Exhibit, 8 - 11 January 2007, Reno, Nevada.

[6] Dalamagkidis K., Valavanis K.P., Piegl L.A., (2008), On unmanned aircraft systems issues, challenges and operational restrictions preventing integration into the National Airspace System, Progress in Aerospace Sciences, Vol. 44, pp: 503-519.

https://doi.org/10.1016/j.paerosci.2008.08.001

[7] B. Gütlich, R. Meyer, S. Philipp-May, and A. Pagels-Kerp, "German Roadmap on Optical Communication in Space," in Advanced Solid-State Lasers Congress, P. McManamon, . Watson, and O. Steinvall, eds., OSA Technical Digest (online) (Optical Society of America, 2013), paper LM1B.2. https://doi.org/10.1364/1sc.2013.1m1b.2

[8] Visconti, G., P. Carlo, et al. (2007). Uninhabited Aerial Vehicles: Current and Future Use. Observing Systems for Atmospheric Composition, Springer New York: 106-118.

[9] Royal Belgian Academy Council of Applied Science (BACAS), Hydrogen as an energy carrier, 2006, http://www.kvab.be/downloads/lezingen/hydrogen_energycarrier.pdf.

[10] Karen Haman, Emily, Stiever, Literature Review of Hydrogen Production, Storage, Distribution and Utilization Technologies, 2006, http://www.iowaenergycenter.org/wp-content/uploads/2013/04/Literatur eReview_Hydrogen2006.pdf.

[11] Nevzet Kaya, Achievable Altitudes for Hydrogen Fueled Fuel Cell Powered Unmanned Air Vehicles, International Conference on Aviation, Energy and Industrial Engineering (ICAEIE-2016) Dec. 30-31, 2016 Dubai (UAE).

[12] SOFCMAN, Improving Power Density of Solid Oxide Fuel Cell Stacks Using A New Contacting Design, http://www.sofc.com.cn/news17.html, Oct, 2015.

[13] Jason Marcinkoski, Jacob Spendelow, Adria Wilson, Dimitrios Papageorgopoulos Fuel Cell System Cost - 2015, US DOE Hydrogen and Fuel Cells Program Record, Oct, 2015.

[14] Alejandro Mendez, Teresa J. Leo, Miguel A. Herreros, Current State of Technology of Fuel Cell Power Systems for Autonomous Underwater Vehicles, Energies, Vol: 7, pp:4676-4693, 2014.

[15] Rocket\&Space Technology, Rocket Propulsion, http://www.braeunig.us/space/propuls.htm, Nov. 2016 